the extraction of uranium and the chemical processing of low-grade beryllium ores has been further curtailed and the effort devoted to fundamental problems in inorganic chemistry increased, while besides flame technology other new techniques like the rotary contractor for solvent extraction from pulps are being applied in a wider context. In the Inorganic Group, studies on the separation of the rare earths have now ceased, as have those on the ultra-purification of elements, and interest has now shifted to the solid-state chemistry of rare-earth compounds. The catalytic properties of europium are proving of interest, as are also the reflectance spectra of the rare earths, while the section set up to work on X-ray diffraction has been widely used and a new section created to deal with electrochemistry.

Considerable changes are taking place in the organic chemical work of the New Materials Group, where the work on boron-nitrogen polymers is being tapered off and comparable study of the less-known organo-aluminiumnitrogen compounds has led to the characterization of low-polymeric substances of a new type and unusual molecular structures. Progress is reported in the synthesis and study of organic semiconducting material and in the understanding of intermolecular electron-transfer processes. Work on the physical chemistry of ion-exchange has now permitted the relations between the selectivity of a resin, its degree of cross-linking and its exchange capacity to be framed in rather general terms, and these investigations, and those of the selectivity and transport process in ion-exchange membranes, are relevant both to technological applications of such materials and to an understanding of membrane phenomena, etc., in biological systems.

The Chemical Thermodynamics Programme has entered a highly productive phase, and during the coming year the responsibilities of the Group will be extended to include a more general concern with chemical physics. The Laboratory is equipped with both static and rotating bomb calorimeters, and besides measurements of the thermodynamic properties of organic oxygen compounds, measurements have been made on organic fluorine compounds to establish bond-energy relations and to provide highly accurate heats of combustion of substances which may be used as secondary standards in the combustion calorimetry of organo-fluorine compounds. Critical temperature measurements have been made on a further eighteen compounds, including twelve substituted phenols with critical temperatures between $420^{\circ}$ and $460^{\circ} \mathrm{C}$, and for the four butanols critical densities and pressures were also measured. An investigation of the thermodynamic properties of non-stoichiometric compounds has been started and a solid-state electrochemical cell constructed. A batch of $m$-ethylphenol with a purity of 99.91 moles per cent has been synthesized from acetophenone as well as highly purified samples of $p$-ethylphenol, diethyl ketone, 3-methyl-6-t.-butylphenol, methyl $n$-propyl ketone and 2 : 5-xylen-1-ol.

In the Corrosion of Metals Group, research on metallic corrosion remains a continuing theme and during the year has been concentrated on corrosion in flowing water; passivation or inhibition and the specific role of the anions in a corrosive solution; and anaerobic corrosion in soils and polluted waters. As well as fundamental studies, work on underground corrosion, essentially microbiological, has included a survey of the aggressiveness of soil at various sites in England and Wales and a continued long-term experiment on corrosion under conditions presented by the River Thames. Topics to which the Isotope Applications Unit has devoted much time to include the possible utilization of the Mössbauer effect for studying structural chemical problems, the labelling and pulverizing of coal, the distribution of activity along threads or wires and liquid scintillation counting. The Director's Research Unit has studied the interaction of oxygen with tungsten surfaces by electron microscopy and the accommodation of copper atoms evaporated into ultra-high vacuum on to a clean tungsten surface.

The staff in post at the end of the year included 54 scientific officers, 7 research fellows, 104 experimental officers, 29 scientific assistants, 2 works technical officers, 20 executive and clerical, and 44 industrial, the authorized complement being 286 compared with 293 at the end of 1961. No progress has been made in relieving the serious shortage of accommodation.

\title{
THE EMPLOYMENT OF CAMBRIDGE GRADUATES
}

\begin{abstract}
7 HE results of a survey, The Employment of Cambridge Graduates*, made by Mrs. Christine Craig to help the University of Cambridge Appointments Boards, has been published by the Cambridge University Press. It covers the present occupation of Cambridge graduates of 1952 and 1953, the levels of responsibility and the salaries they have attained, the satisfaction they derive from their occupations and how they have progressed to their present positions. 'The questionnaires were sent out during July and August 1961, and completed questionnaires were received from 2,630 men and 494 women, or 70 per cent of all the men and 80 per cent of all the women graduates on the College lists for the appropriate years. The results are presented in six chapters covering, respectively, the graduates' background, their current employment, earnings and satisfaction of those working in the United Kingdom, the past and the future, men working overseas, and the women graduates.
\end{abstract}

Both men and women come of predominantly bourgeois background, only 2 per cent of the men being childron of semi-skilled or unskilled workers. Nearly two-thirds of men, but a lesser proportion of the women, were educated at independent schools, but whilo most women went direct to Cambridge from school, only 17 per cent of the men did so, 66 per cent being otherwise occupied for one

\footnotetext{
* The Employment of Cambridge Graduates. By Christine Craig. Pp. $\mathrm{xi}+$ 102. (Cambridge: At the University Press, 1963.) $10 s$.
}

to three years, usually in National Service. Of the men, 31 per cent graduated in science or mathematics, 11 per cent in engineering, 9 per cent achieving first-class honours, 59 per cent second-class honours and 6 per cent an ordinary degree. Most of the men were in the age-group 29-33 and all but 434 were working in the United Kingdom, 349 of those being British nationals. At the time of the survey, 35 per cent of the women were working full time and 16 per cent part time, and out of 207 married women, 50 were working full time and 78 per cont part time, a very high proportion being teachers in schools and universities.

Of all men working in tho United Kingdom, about 24 per cent were employed in teaching and 24 per cent in industry, of whom about a quarter were employed in research, design and development work, a similar proportion in sales and marketing, less than a fifth in production management and a slightly smaller proportion in general management. Of the teachers, three-fifths were schoolmasters, of whom only a quarter were teaching science, mathematics or engineering subjects, whereas in the universities and technical colleges, men teaching the latter subjects outnumbered those teaching arts subjects in the proportion $57: 43$. Medicine and commerce each claimed about 8 por cent of the whole group; 9 per cent were public servants in the Civil Service, local authoritios or the Atomic Energy Authority (4 per cent in the Scientific Civil Service, 3 per cent in professional or specialist classes, 
2 per cent in administration). Nearly 60 per cent of engineering graduates and 41 per cent of scientists and mathematicians were in industry, about 20 per cent of the latter being in universities and technical colleges and 16 per cent teaching in schools. About two-fifths of the arts men in industry were in commercial departments and a quarter in general management or the central services of industrial groups.

More than a third of all men with first-class honours were in university posts, about one in seven being in industry and professional practice. Only three schoolmasters in 100 had first-class honours and nearly 10 per cent had ordinary degrees. Most Ph.D.s were in universities or had research appointments elsewhere. Taking the total earnings, the middle members of the group of men working in the United Kingdom were receiving $£ 1,500$ $£ 1,600$; for basic earnings, the medium was $£ 1,425$, but for a quarter total earnings were less than $£ 1,250$; for another quarter they exceeded $£ 2,000$, and for 12 per cent $£ 2,500$. A third of the men in industry were earning more than $£ 2,000$, but nearly a quarter less than $£ 1,500$. Three-quarters of the schoolmasters fell in the group earning between $£ 1,000$ and $£ 1,500$ and only 3 per cent were earning more than $£ 2,000$, while only 7 per cent of university and technical college teachers earned more than $£ 2,000$. Teaching was the only occupation in which the men who considered their salary a fair return were outnumbered by those who thought otherwise, but oven so, 50 per cent were satisfied. About a third of those employed in universities, in medicine and in private practice were dissatisfied, and about a quarter in industry.
About 30 per cent of men in the universities expressed profound satisfaction. Men who entered paid employment within six months of graduation were mostly paid $£ 400-$ $£ 600$ a year, and for four years after graduation the average salaries of men who had taken postgraduate courses were slightly lower than those of men who had entered employment immediately after graduation. While only 3 per cent of the men who went into the Church ( 6 per cent of the total) or the medical profession afterwards changed their profession, 58 per cent of the others changed their employers at least once between starting their first job and the time of the survey, 16 per cent making radical changes of occupation. About half the men expected to be with the same employer or in the same business in five years time.

Of the 434 men working overseas, 60 were in the United States, 58 in Canada and 131 in various African territories, and it is probable, but not certain, that at least half of those in Canada and a substantial proportion of those in the United States were permanently resident overseas. Of the 19 per cent in Government service, most were in Africa; 20 per cent were concerned with education in schools, 7 per cent were employed in universities, mostly in the United States, 20 per cent in industry and 13 per cent in commerce. Of the scientists and mathematicians, 16 per cent, and of the engineers 13 per eent, were overseas, 25 engineers or scientists being in the United States and 20 in Canada; of the 29 Ph.D.s overseas, 17 were in the United States, almost all in university posts. A third of the men overseas were earning the equivalent of $£ 3,000$ or more.

\title{
RIOMETER OBSERVATIONS OF IONOSPHERIC ABSORPTION DUE TO THE SOLAR FLARES OF APRIL 15, 1963
}

\author{
By S. HOROWITZ \\ Air Force Cambridge Research Laboratories, Bedford, Massachusetts \\ AND \\ S. C. GOLDMAN \\ Aerospace Research, Inc., Boston 35, Massachusetts
}

$\mathrm{T}$ HE occurrence of a strong solar flare offers an excellent opportunity for determining the dependence of ionospheric absorption on the zenith angle of the incoming ionizing radiation. Early calculations for a simple Chapman layer ${ }^{1}$ indicated a dependence of the absorption on the zenith angle $\theta$ of the form $(\cos \theta)^{3 / 2}$. Some recent experimental and theoretical results show that the 3/2 power is generally too high an exponent. Calculations by Nicolet ${ }^{2}$ have shown that an important parameter in determining the dependence of absorption on zenith angle is the effective recombination coefficient $\alpha$. The classical derivation assumes that both $\alpha$ and $H$, the scale height, are constant. However, this is not the case in any of the ionospheric regions. A recent work by Mitra and Jain $^{3}$ also considers the variability with altitude of $\alpha$.

A riometer network, installed by the Air Force Cambridge Research Laboratories at various locations around the world, has yielded absorption data on the two Type $\mathrm{II}^{+}$solar flares which occurred on April 15, 1963, beginning at 1123 U.T. and 1614 U.T., respectively. The first flare was accompanied by a severe noise storm which began about ten minutes after the conclusion of the first major period of absorption. All the riometers located on the sunlit side of the Earth observed these flares and absorption data obtained are given in this paper. The dependence of absorption on zenith angle is quite close to the value obtained by Appleton.

Riometer locations. Riometers which observed the solar flares of April 15 are listed in Table 1, along with the solar zenith angles at flare onset. All operating frequencies were $30 \mathrm{Mc} / \mathrm{s}$ with the exception of Bedford, Massachusetts, which also operated at $22 \mathrm{Me} / \mathrm{s}$, and Athens, Greece, where data was also obtained on $27.6 \mathrm{Mc} / \mathrm{s}$ and $58 \mathrm{Mc} / \mathrm{s}$.

Table 1. Solar Zenith ANGees at 1123 U.T., Aprit 1.5, 1963. Computed FOR RIOMETER SITES Site locations

Accra, Ghana
Addis Ababa, Ethiopia
Athens, Greece
Hermanus, Republic of South Afrioa
New Delhi, India
Bedford, Massachusetts
Solar zenith angle $10^{\circ}$
$29^{\circ}$
$34^{\circ}$
$45^{\circ}$
$63^{\circ}$
$76^{\circ}$

Table 2 lists solar zenith angle information for the flare of 1614 U.T., April 15, 1953.

Table 2. Solar Zentth ANate at 1614 T.T., Aprtu 15, 1963. COMPUTED FOR RTOMETRR SITES

\begin{tabular}{|c|c|}
\hline Site locations & Solar zenith angle \\
\hline $\begin{array}{l}\text { Bedford, Massachusetts } \\
\text { Sacramento Peak, New Mexico } \\
\text { Great Whale River, Quebec } \\
\text { Accra, Ghana } \\
\text { Athens, Greece }\end{array}$ & $\begin{array}{l}34^{\circ} \\
45^{\circ} \\
47^{\circ} \\
62^{\circ} \\
80^{\circ}\end{array}$ \\
\hline
\end{tabular}

Antennæ used were two-element, vertically directed Yagis operating over an artificial ground screen. Antenna beam-width was about $60^{\circ}$ in the $E$-plane.

Absorption data. In some of the measurements, local interference was quite severe, and the accuracy of the measurements was somewhat degraded. However, at 